https://doi.org/10.7203/Celestinesca.6.19554

\author{
$6 \longdiv { 0 }$ \\ "EClipse AY MAÑANA, LA PUENTE es LlEvadA. . . .": DOS \\ NOTAS SOBRE LA FECHA DE CELESTINA \\ J. J. Rozemond \\ Utrecht
}

\title{
Introducción
}

En el acto $3^{\circ}$ de Celestina aparece una serie de observaciones de parte de Sempronio: sirve como ejemplos de diversa índole para indicar que por más radical que sea un determinado suceso, con el tiempo se hace a la idea. Se trata de este pasaje:

Cada día vemos novedades y las oýmos y las passamos y dexamos atras. Diminúyelas el tiempo, fázelas cotingible. ¿Qué tanto te maravillarías si dixesen: la tierra tembló, o otra semejante cosa, que no olvidases luego? Assí como: elado está el río, el ciego vee ya, muerto es tu. padre, un rayo [cayó], ganada es Granada, el rey entra oy, el turco es vencido, eclipse ay manana, la puente es llevada, aquél es ya obispo, a Pedro robaron, Ynés se ahorcó. ¿Qué me dirás, sino que a tres días passados, o a la segunda vista, no ay quien dello se maraville? I (énfasis mío)

La mayoría de estas enunciaciones se pueden considerar como tópicos. Sin embargo, en el siglo pasado ha habido algunos críticos que atribuían un sentido histórico a algunas de ellas. Al inventariar las supuestas relaciones entre las locuciones y ciertos acontecimientos históricos, topé con una incongruencia, perpetrada por R. Foulché-Delbosc.

Me parece interesante relatarla en este artículo, con el objeto de determinar con más precisión la fecha de composición de Celestina, de la cual Humberto López Morales, en su edición crítica, ha dicho:

Las fechas de la biografía de Rojas, deducidas hasta hoy, hacen prácticamente imposible pensar que la Comedia hubiese podido terminarse antes de 1492.2

Entre otras cosas, este ensayo de determinación más exacta será efectuado por medio de datos no disponibles anteriormente. Al lado de la falta cometida por Foulché-Delbosc, quisiera destacar otra locución, con el mismo objeto. 
Es curioso que esta locución sea la única en la serie con un sentido de futuro: mañana. Pero aparte de eso: ¿a qué se referiría? El eclipse de que habla Sempronio, si es que es histórico, no debió necesariamente ocurrir en España, ni mucho menos durante la estancia de Rojas en Salamanca. Sin embargo, Foulché-Delbosc atribuyó a1 fenótneno un sentido histốrico, con el objeto de indicar un terminus postquom (la fecha del eclipse) para la composición de Celestina, así como lo hicieron otros críticos. E1 situaba la composición de Celestina antes de 1492. Al estudiar los eclipses en el siglo $\mathrm{XV}_{3}$ ocurre que entre 1494 y 1502 , los años que Rojas estudiaba en Salamanca, 3 no hubo ningún eclipse en Europa, ni total, ni parcial.

Ocurren en la vida de Rojas hasta 1500 sólo dos eclipses que alcanzaron a España. Uno, de 1478 , cuya zona de totalidad pasó por Salamanca, Madrid y Valencia. Pero Rojas, nacido alrededor de 1474, no lo habrá recordado. E1 segundo eclipse es más interesante. Ocurrió en 1485, con una totalidad, dicho sea, que solamente oscureció el extremo noroeste de la penÍnsula ibérica y que pasó después por el mar cantábrico, el centro de Francia, Munich y Viena. Pero la zona sur del eclipse parcial cubrió toda España. El año hace muy probable que Rojas, teniendo once años, por 1o menos se acordara de este eclipse. Por tanto, no sería de extrañar que Rojas usase este suceso, así como se refleja, según Gilman, el recuerdo personal de Rojas en el pasaje en el acto XII, donde Sempronio habla de Mollejas el Hortelano. 4 Veamos ahora lo que opinaba Foulché-Delbosc. El erudito francés asumía que el eclipse que menciona Sempronio era el del 17 de mayo, 1482. Apoya su argumentación así:

"1482, 17 mai, à cinq heures et demie du soir; visible dans 1'Europe de 1 'Ouest et I'Afrique de Nord-Ouest. . ."

Pero ¿por qué ha omitido Foulché-Delbosc la última parte de esta referencia? Lee: "centr. 64. A"6, 10 que quiere decir que el centro del eclipse (la zona de totalidad) pasó por $64^{\circ}$, latitud norte. La A significa eclipse anular.

En 1482, Rojas tenía unos ocho años y vivía en La Puebla de Montalbăn. Esta villa se encuentra a $40^{\circ}$, latitud norte. Preguntándome cuál habrá sido la visibilidad de este eclipse en La Puebla, me dirigí al departamento de astronomía de la universidad de Utrecht. Resultó que existe un programa de computadora, que es capaz de calcular el grado de oscurecimiento de un determinado eclipse en cualquier lugar del mundo. Aplicado este programa a dicho eclipse, postulando La Puebla como sitio de observación, mostró que la visibilidad del eclipse (icuyo centro se encontró en el noroeste de $\mathrm{Ru}-$ sia!) no era muy grande: sólo la novena parte del disco solar quedó cubierta.

El esquema siguiente muestra el porcentaje de oscurecimiento del disco solar en caso de los respectivos eclipses: 
29 de julio

17 de mayo 1482

16 de marzo

1485

8 de mayo

En Salamanca

Considerando este esquema, también puede haber sido el eclipse de 1491 al que se refiere Sempronio, pero el de 1482, jamás. La distancia entre este eclipse y España hace muy Improbable que aquél se viera en La Puebla, o en cualquier otro lugar de España. La evidencia presentada aquí muestra que Foulché-Delbosc escribió con poco escrutinio. Parece extraño que, teniendo la referencia a la vista, no la citara integralmente.

\section{"La puente es IZevada"}

Este décimo ejemplo de Sempronio no es discutido mucho en la crítica celestinesca. De hecho dos son las puentes que entran en cuenta: una es la puente de Alcántara (Toledo). de la cual se hundió un arco que fue reparado en $1484 ;^{7}$ la otra es 1 a de Tormes, en Salamanca. A finales de 1498, hubo en esa ciudad lluvias extraordinarias y persistentes. Juan del Encina se refiere a este temporal en su Egloga IX, también llamada Egloga de las grondes Zzuvias, con estas palabras:

\section{con los andiluvios grandes}

no quedan vados ni puentes

y después:

$$
\text { y ha dos meses que llueve. }
$$

Sitúa los sucesos así:

Año de noventa y ocho $y$ entrar en noventa y nueve ${ }^{8}$

\section{Espinosa Maeso escribió:}

Tales lluvias trajeron por consecuencia que saliéndose de madre el río Tormes, derribara dos arcos de la puente, según nos ínformó una cédula real expedida en Madrid, [que ordenaba] la restauración "de los grandes daños y pérdidas a esta ciudad, entre las cuales derrocó dos arcos de la puente."

Gilman dice que "lo cierto es que (. . .) al menos algunas partes de La Celestina fueron escritas en Salamanca durante las vacaciones de pascua de 1497 ó 1498. Probablemente este último año. . . ."10

Si es que Rojas, por medio de Sempronio, al decir "la puente es lleva$\mathrm{da}^{\prime \prime}$, se refiere a las lluvias torrenciales del $\mathrm{f}$ in de 1498 , es muy seductor concluir que apenas puede haber una edición anterior a la de 1499 . Tenien- 
do en cuenta el tiempo necesario para imprimirse una obra, incluso .. se podría llegar a sentar que la edición de Burgos de 1499 (fecha comúnmente aceptada, pero no segura) sería más bien de 1500 .

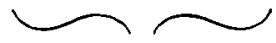

NOTAS

1 Fernando de Rojas. La Celestina. Edición, introducción y notas de Humberto López Morales. Col. Hispánicos Planeta, Cupsa Ed.: Madrid, 1976, pp. $67-68+\mathrm{n}$.

2 Ibid., p. $67, \mathrm{n} 6$.

3 S. Gilman, La España de Fermondo de Rojas. Ponorama intelectual y social de La Celestina (Madrid: Taurus, 1978), p. 272.

4 s. Gilman, "Mollejas el ortelano." En Estudios dedicados a James Homer Herriott (Madison: Univ. of Wisconsin Press, 1966), pp. 103-107.

5 Citado por R. Foulché-Delbosc en: "Observations sur La Celestine." Revue Hispanique 9 (1902), 182n.

6 De hecho, esta referencia y la anterior proceden de: L'Art de vérifier les dates des faits historiques, des chartes, des chroniques, et autres anciens monuments depuis la naissance de Notre Seigneur (Paris, 1783), I, 79 .

7 R. Espinosa Maeso, "Dos notas para La Celestina". Boletin de la Real Academia Española 13 (1926), 183.

8

Ibid.

9 Ibid., p. 184.

10 La España de Fermando de Rojas, p. 270. 